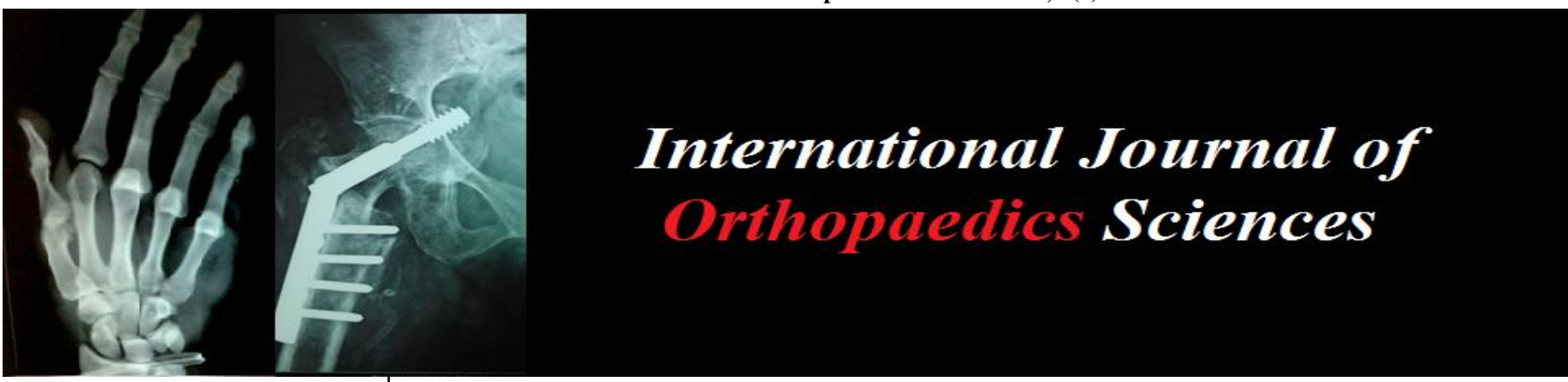

ISSN: $2395-1958$

IJOS 2018; 4(1): 1043-1048

(C) 2018 IJOS

www.orthopaper.com

Received: 22-11-2017

Accepted: 25-12-2017

\section{Mahesh KU}

Professor, Department of orthopaedics, Sri Siddhartha Medical College, Siddhartha Academy of Higher Education University, Tumkur, Karnataka, India

\section{Jayagopal C}

Junior Resident, Department of orthopaedics, Sri Siddhartha Medical College, Siddhartha Academy of Higher Education University, Tumkur, Karnataka, India

\section{Madhusudan H}

Junior Resident, Department of orthopaedics, Sri Siddhartha Medical College, Siddhartha Academy of Higher Education University, Tumkur, Karnataka, India

\section{Manu KT}

Junior Resident, Department of orthopaedics, Sri Siddhartha Medical College, Siddhartha Academy of Higher Education University, Tumkur, Karnataka, India

\section{Correspondence}

Mahesh KU

Professor, Department of orthopaedics, Sri Siddhartha Medical College, Siddhartha Academy of Higher Education University, Tumkur, Karnataka, India

\section{To assess the functional outcome of autologous platelet rich plasma injection in patients with chronic plantar fasciitis}

\author{
Mahesh KU, Jayagopal C, Madhusudan H and Manu KT
}

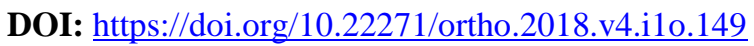

\section{Abstract}

Introduction and Objectives: Plantar fasciitis most common degenerative condition causes severe heel pain near the site of origin of the plantar fascia. Any heel pain due to plantar fasciitis persisting will often distress the patient, so right intervention at the right time is needed. Intra-lesional steroid is being used widely, but it has its own side effects. New studies have shown PRP promote removal of necrotic tissue but also enhance tissue regeneration and improve symptoms. We studied to assess the Functional outcome of autologous platelet rich plasma injection in patients with chronic plantar fasciitis.

Objectives: To evaluate Functional outcome of autologous platelet rich plasma injection in patients with chronic plantar fasciitis.

To recognize any complications associated with platelet rich plasma injection.

Materials and Methods: A prospective study was done at Sri Siddhartha Medical College, Hospital \& Research Center, from October 2015 to April 2017. Inclusion criteria include plantar heel pain longer than 6 weeks, failed conservative management of at least 4 weeks duration. In 100 patients, single dose of autologous PRP injection was given and followed up for 6 months. Patients assessed functionally using AOFAS, VAS scores and recorded before treatment and on follow-up at 1st month, 2nd month, 4th month, and 6th month.

Results: We had highest number of patients in age group between 31 to 50 years.

Out of 100 patients, 60 patients had $100 \%$ pain relieved, 28 patients had more than $50 \%$ pain relieved, 8 patients had less than $50 \%$ pain relieved and 4 patients had no pain relief. No other complications were seen in any patients. VAS and AOFAS score were statistically significant at follow ups ( $p$ value is $<0.0001)$.

Conclusion: PRP is a biological option for a common orthopaedic and recalcitrant orthopaedic problem like heel pain/plantar fasciitis. Our study has shown that autologous PRP injection is more effective treatment for long term relief of chronic heel pain.

Keywords: Plantar Fasciitis, platelet rich plasma

\section{Introduction}

Plantar fasciitis is a common pathological condition affecting the hind foot and can often be a challenge for clinicians to successfully treat. ${ }^{[1]}$ It is an overuse injury causing inflammation at the origin of the plantar fascia and surrounding perifascial structures, such as the calcaneal periosteum. It is the most common clinical problem that causes inferomedial heel pain in adults. ${ }^{[2]}$

Lapidus and Guidotti ${ }^{3}$ in 1965 found that the number of patients in their foot clinic with plantar fasciitis was greater than those with any other recorded foot lesion. Regarding the history of this disease plantar fasciitis is an overuse syndrome has been recognized for almost two hundred years ago by an author named woods ${ }^{[4]}$ and other authors stated that plantar fasciitis is called by different names they are heel pain syndrome, subcalcaneal pain syndrome calcaneodynia, subcalcaneal bursitis, calcaneal periostitis, neuritis, heel syndrome, subcalcaneal spur syndrome, stone bruise, medial arch sprain, runner's heel, jogger's heel, and policeman's heel [4]. Due to multifactorial ${ }^{[5,6]}$ causes of plantar fasciitis the treatment modalities are wide in number to relieve pain NSAIDS, night splints, low dye taping, heel pads, cups, orthoses, steroid injection, extra corporeal shock wave therapy were used. 
Only 5 to $10 \%$ of the people will need surgical intervention like removal of calcaneal spur, neurectomy, and plantar fasciotomy can often be a challenge to clinician for successful treat ${ }^{[1]}$.

Among above mentioned treatments steroid injection is a popular method of treating the condition but only seem to be useful in the short term and disappointing long-term results. Potentially disabling complications have also been reported, such as rupture of the plantar fascia, infection, and fat pad atrophy.

The advent of platelet rich plasma for treatment of plantar fasciitis in recent times is due to its wide advantages with early recovery of pain levels and improved functional activities of the patient in comparison with above mentioned treatments.

Platelet rich plasma (PRP) is defined as a volume of the plasma fraction of autologous blood having a platelet concentration above baseline. By injecting an aliquot of concentrated platelet enriched plasma into a localized area introduces platelets into tissue to stimulate a supraphysiologic release of growth factors in an attempt to "jumpstart" the regenerative process in degenerative conditions and reduce pain.

In this study we have tried to evaluate functional outcome of autologous platelet rich plasma injection in patients with chronic plantar fasciitis and to recognize any complications associated with platelet rich plasma injection.

\section{Methods}

All patients with heel pain presented to outpatient Department of Orthopaedics at Sri Siddhartha Medical College, Hospital, Tumkur were included in this study after obtaining their informed and valid written consent. This study was undertaken from October 2015 to April 2017. Clearance from institutional ethical committee was obtained before initiating the study.

\section{Method of collection of data Sample Size}

100 patients with heel pain who were not responding to conservative management and who gave the consent for platelet rich plasma injection during the period of study were included as study sample.

Initial Assessment: Patients were assessed clinically, a thorough history and clinical

Examination was carried out, the subjective symptoms and objective signs were recorded in a proforma. This was followed by routine investigations as well as an X-ray of the heel and ultrasound of the plantar fascia of all the patients to rule out the other causes that cause heel pain. The study is conducted for a period of 6 months on a patient. The functional assessment was done using VAS, AOFAS scores recorded before treatment and follow up at 1st month, 2nd month, 4th month and 6th month based on following criteria.

\section{Inclusion Criteria}

1. Patient with complaints of plantar heel pain worse on rising in the morning.

2. Failed conservative management of at least 4 weeks duration.

3. Patient with no previous local steroid injection in last 2 months.

4. Patient with age above 18 years.

\section{Exclusion criteria}

1. Patient with known case of Diabetes mellitus.

2. Patient with Osteoarthritis of ankle.

3. Patient with Infection or ulcer at the injection site.

\section{Preparation of PRP}

Platelet rich plasma was prepared using double spin centrifugation method of Augustus D et al. $10020 \mathrm{ml}$ of venous blood is drawn from cubital vein. The blood is immediately transferred into six $2.7 \mathrm{ml}$ vaccutainers prefilled with acid citrate dextrose. $2.7 \mathrm{ml}$ Acid citrate dextrose containing vaccutainers are readily available in hospital. All the containers are filled till the markings on the vaccutainers. The vacationers are then placed in the slot available in the centrifugation machine in such a way that they are counter balanced. The initial centrifuge was done at 1500 rotations per minute for three minutes. This separates the blood into two layers. $\mathrm{RBC}$ rich at the bottom and plasma along with the platelets are at the top (figure 13). The top layer is then transferred to fresh vaccutainers using a long $18 \mathrm{G}$ needle and syringe. The vaccutainers are now again centrifuged at 2500 rotations per minute for three minutes. This separates the column of plasma to platelet rich at the bottom and platelet poor at the top. Using a long $18 \mathrm{G}$ the top half column which is platelet poor is discarded. The platelet rich plasma at the bottom is now collected from the vaccutainers and is now ready for use.

After the preparation of PRP, the cell counts in the sample are assessed using the beckman coulter cell counter machine. The platelet count in the sample ranged from 2.1 to 5.9 lakhs.

\section{PRP Injection Technique}

The procedure is explained to the patient, consent is obtained. Patient in supine position, involved foot is identified. The part was cleaned \& prepared with spirit \& povidone iodine. The site of maximal tenderness i.e. medial aspect of the foot at the origin of plantar fascia usually is marked using a marker. Under aseptic precaution using a $21 \mathrm{G}$ and $11 / 2$ inch needle, $1 \mathrm{ml}$ PRP is injected initially over the maximum tender point and needle is partially withdrawn and multiple punctures are made in the surrounding tissue (peppering technique). The remaining $1 \mathrm{ml}$ of platelet rich plasma was injected in surrounding tissue.

\section{Aims and Objectives \\ Aim of the Study}

To Assess the Functional outcome of autologous platelet rich plasma injection in patients with chronic plantar fasciitis.

\section{Objectives of the Study}

1. To evaluate Functional outcome of autologous platelet rich plasma injection in patients with chronic plantar fasciitis.

2. To recognize any complications associated with platelet rich plasma injection.

\section{After Treatment \\ Post Injection Care}

Post injection, patients are rested for $15 \mathrm{~min}$ and then allowed to walk. As PRP effectively induces an inflammatory response, some patients experienced minimal to moderate discomfort following the injection which may last for up to 1 week. They were instructed to ice the injected area if needed for pain control and modify activity as tolerated. We recommended acetaminophen as the optimal analgesic, and 
avoided use of NSAID“s.

After 48 hours, patients are given a standardized stretching protocol to follow for 2 weeks. A formal strengthening program is initiated after this stretching. Patients are advised to avoid strenuous activities and rest for 2 weeks. No aggressive running or jumping activities are allowed for 2 weeks. At 4 weeks after the procedure, patients are allowed to proceed with normal sporting or recreational activities as tolerated. MCR footwear was advised to use.

\section{Follow-up}

Patients are followed up at 1st, 2nd, 4th month and 6th month. VAS, AOFAS outcomes are compared with previous visits at each follow-up.

The SPSS software version 16.0 was used to do statistical analysis by comparing the results of 1st month, 2nd month, 4th month and 6th month. The Data was assessed using Student T test. P-value $<0.05$ was considered as statistically significant.

\section{Results}

\section{Age Distribution}

A total of 100 cases were included of which 22 cases were below 30 years of age, 31 to 40 years 37 cases, 41 to 50 years 33 cases and above 50 years 8 cases.

The mean age obtained from our study was $39.36 \pm 9.26$ yrs.

\section{Sex Distribution}

In the present study, out of 100 cases 32 were males and 68 were females. The male to female ratio is $1: 2.12$.

\section{Side Affected}

In our study of 100 cases 59 patients were right sided and 41 patients were left sided.

\section{Mean Pain Score}

Patients were analyzed for pain relief subjectively at 1 st month, 2nd month, 4th month and 6th month.

Pain score was assessed at the time of injection. The mean pain score of all the patients at the time of injection was $8.804 \pm 1.288$. The mean pain score at 1 st month, 2 nd month, 4th month, 6th month was $6.980 \pm 1.592,5.088 \pm 1.623$, $2.990 \pm 1.686$ and $1.186 \pm 1.892$ respectively.

\section{Duration of Symptoms}

Out of total 100 patients 84 patients had symptoms of less than one year duration, 16 patients had pain for more than one year before coming here for treatment. All patients had conservative treatment for at least three months.

\section{Duration of Symptoms and Pain Relief}

Analysis was done based on the duration of symptoms and ultimate pain relief. 15 out of the 23 patients with pain of less than 6 months, 35 out of 61 patients with duration of symptoms between 6-12 months and 10 out of 16 patients with symptoms of greater than one year had complete relief of pain. 3 out of 61 patients with pain for 6-12 months and 1 out of 16 with pain greater than 1 year duration had no improvement of symptoms at six months. Duration of symptoms had no significant correlation with the clinical outcome after injection.

\section{Percentage of Pain reduction related to duration of post PRP injection in patients}

Patients were analysed for percentage reduction of pain.
Percentage reduction of pain is obtained by calculating the percentage of the difference of pain score at every follow up from initial pain score at the time of injection. Out of the 100 patients, 3 patients had $100 \%$ pain relief at 2nd month, 14 patients had $100 \%$ pain relief at 4th month, and 60 patients had $100 \%$ pain relief at 6th month follow up. However 28 patients had significant relief of pain (More than $50 \%$ pain relief) at the end of 6 months. 8 patients had pain relief less than $50 \%$ and 4 patients out of 100 the pain was not relieved at the end of 6 months.

\section{Mean Vas Score Value}

In this study mean VAS score was 8.804 at the time of injection, and 1st month follow up showed mean of 6.980, 2nd month mean was 5.088, 4th month mean was 2.990 and 6th month was 1.186

\section{Comparison of Vas Score}

Comparison was made between mean VAS score at the time of injection and 1st month, between 1 st and 2nd, 2nd and 4th, 4 th and 6th, 2nd and 6th, at the time of injection and 6th month.

Comparision was analyzed by using student's t-test.

\section{Mean American Orthopaedic Foot and Ankle Society (AOFAS)}

In this study mean AOFAS score was 8.804 at the time of injection, and 1st month follow up showed mean of $6.98,2$ nd month mean was 5.088, 4th month mean was 2.990 and 6th month was 1.186 .

\section{Comparison of AOFAS Score}

Comparison was made between mean AOFAS score at the time of injection and 1st month, between 1st and 2nd, 2nd and 4th, 4th and 6th, 2nd and 6th, at the time of injection and 6th month.

Comparison was analyzed by using student's t-test.

\section{Discussion}

In this study VAS score and AOFAS score $\mathrm{p}$ values found to be statistically significant in every follow up $(P<0.0001)$. Pankaj mahidhar et al. ${ }^{[7]}$ also showed there was a significant improvement AOFAS score in PRP group than steroid group with significant $P$ value. Mean visual analogue scale and AOFAS scores improved over time after injection in PRP group. In PRP group, visual analogue scale score decreased significantly from pre injection level at follow-up of 3 weeks $(\mathrm{P}=0)$ and 3 months $(\mathrm{P}=0)$. Compared with the pre injection level, AOFAS score improved significantly at follow-up of 3 weeks $(\mathrm{P}=0)$ and 3 months $(\mathrm{P}=0)$.

In similar study Ferhat say et al. ${ }^{[8]}$ showed PRP group had significantly higher mean AOFAS and mean VAS scores at follow-up than the steroid group. $\mathrm{P}$ value significant $(p<0.0001)$.

In similar study by Ragab EM, Othman AM et al. ${ }^{[9]}$ using a visual analogue pain scale, the average pre-injection pain in patients of was 9.1. Average post-injection pain decreased to 1.6. Twenty-two patients (88\%) were completely satisfied, two patients $(8 \%)$ were satisfied with reservations, and one patient $(4 \%)$ was unsatisfied with using the visual analogue scale. None of the patients experienced any complications from PRP injection at the end of follow-up period.

In our study using a visual analogue pain scale, the average pre-injection pain in patients of was 8.8. Average postinjection pain decreased to 1.18. 60 patients were $100 \%$ 
completely satisfied, twenty eight patients were satisfied moderately $(>50 \%)$ and eight patients were mildly satisfied $(<50 \%)$ and 4 patients were unsatisfied. None of the patients experienced any complications from PRP injection at the end of follow-up period.

The most common secondary level treatment for plantar fasciitis is the use of corticosteroid injections.

However its use is limited to only short term relief19 and the rate of complications can go as high as $50 \%$ in long term ${ }^{[10,11]}$.

A Cochrane review showed that corticosteroid injections 'effectiveness is reduced when used beyond six months. ${ }^{[12]}$

Ideal treatment for plantar fasciitis has not been determined yet.

With advent of biological treatments in orthopaedics platelet rich plasma has been used in many clinical problems viz., wound haemostatic, healing, augmentation of bone grafts, ACL injuries and treatment of tendinitis.

Our study was designed to study the effects of PRP in the treatment of plantar fasciitis in the long term.

A single dose of PRP manually obtained from the patient was found to be satisfactory in reducing the pain and improving functional outcome in the course of 6 months as shown above. The etiology of plantar fasciitis has not fully been studied and so is yet not totally known. The commonly accepted theory in literature is an inflammatory response to micro-tears due to mechanical loading. However Lemont et al [Lemont $\mathrm{H}$, Emirati KM, Use N. Plantar fasciitis: a degenerative process (fasciitis) without inflammation. J Am Podiatry Med Asoka 2003; 93:234-7.]. reported no histological findings in his samples.

The lack of inflammatory findings may shed some light on why steroids fail in the long term.

Platelet-rich plasma stimulates the proliferation of various cell types in cells and tissue [Lucarelli E, Beccheroni A, Donati D, Sangiorgi L, Cenacchi A, Del Vento AM, et al. Plateletderived growth factors enhance proliferation of human stromal stem cells. Biomaterials 2003; 24:3095-100] and activates repair cells in the blood circulation. [Kajikawa Y, Morihara T, Sakamoto H, Matsuda K, Oshima Y,

Yoshida A, et al. Platelet-rich plasma enhances the initial mobilization of circulation-derived cells for tendon healing. J Cell Physiology 2008; 215:837-45.]. More than 30 bioactive proteins are found within the alpha granules of platelets. [Anitua E, Andia I, Ardanza B, Nurden P, Nurden AT. Autologous platelets as a source of proteins for healing and tissue regeneration. Thromb Haemost 2004; 91:4-15.]. These factors activate cells that promote tissue healing.

Our study shows the efficacy of using PRP for plantar fasciitis supporting many other similar studies conducted solely studying PRP or comparing PRP with other modes of treatment.

\section{Age Distribution}

Table 1

\begin{tabular}{|c|c|c|}
\hline Age group & Number of Patients & Percentage \\
\hline $21-30$ & 22 & $22 \%$ \\
\hline $31-40$ & 37 & $37 \%$ \\
\hline $41-50$ & 33 & $33 \%$ \\
\hline $51-60$ & 8 & $8 \%$ \\
\hline
\end{tabular}

\section{Sex incidence}

Table 2

\begin{tabular}{|c|c|c|}
\hline Gender & Number of Patients & Percentage \\
\hline Male & 32 & $32 \%$ \\
\hline Female & 68 & $68 \%$ \\
\hline
\end{tabular}

Side of Fracture

Table 3

\begin{tabular}{|c|c|c|}
\hline Affected Side & Number of Patients & Percentage \\
\hline Right & 59 & $59 \%$ \\
\hline Left & 41 & $41 \%$ \\
\hline
\end{tabular}

Percentage of Pain reduction related to duration of post PRP injection in patients

Table 4

\begin{tabular}{|l|l|l|l|l|}
\hline $\begin{array}{l}\text { Post PRP } \\
\text { injection } \\
\text { follow up }\end{array}$ & $\begin{array}{l}100 \% \text { Pain } \\
\text { relief }\end{array}$ & $\begin{array}{l}50-99 \% \\
\text { pain relief }\end{array}$ & $\begin{array}{l}<50 \% \text { pain } \\
\text { relief }\end{array}$ & $\begin{array}{l}0 \% \text { pain } \\
\text { relief }\end{array}$ \\
\hline $1^{\text {st }}$ month & - & 7 & 73 & 20 \\
\hline $2^{\text {nd }}$ month & 3 & 24 & 69 & 4 \\
\hline $4^{\text {th }}$ month & 14 & 65 & 17 & 4 \\
\hline $6^{\text {th }}$ month & 60 & 28 & 8 & 4 \\
\hline
\end{tabular}

Table 5

\begin{tabular}{|c|c|c|c|}
\hline Duration & 3-6 months & 7-12 months & More than 1 year \\
\hline Number of patients & 23 & 61 & 16 \\
\hline Percentage & $23 \%$ & $61 \%$ & $16 \%$ \\
\hline
\end{tabular}

Duration of symptoms

\section{Duration of Symptoms and Pain Relief}

Table 6

\begin{tabular}{|c|c|c|c|c|}
\hline & $\mathbf{1 0 0 \%}$ Pain relief & $\mathbf{5 0 - 9 9 \%}$ pain relief & $<\mathbf{5 0 \%}$ pain relief & $\mathbf{0} \%$ pain relief \\
\hline 3-6 months & 15 & 5 & 3 & 0 \\
\hline $7-12$ months & 35 & 19 & 4 & 3 \\
\hline$>1$ year & 10 & 4 & 1 & 1 \\
\hline
\end{tabular}

Table 7: VAS Score

\begin{tabular}{|c|c|c|c|c|}
\hline Variables & Minimum & Maximum & Mean & Standard Deviation \\
\hline At the time of Injection & 6.0 & 10.0 & 8.804 & 1.288 \\
\hline $1^{\text {st }}$ Month & 3.0 & 9.0 & 6.980 & 1.592 \\
\hline $2^{\text {nd }}$ Month & 0.0 & 8.0 & 5.088 & 1.623 \\
\hline $4^{\text {th }}$ Month & 0.0 & 7.0 & 2.990 & 1.686 \\
\hline $6^{\text {th }}$ Month & 0.0 & 7.0 & 1.186 & 1.892 \\
\hline
\end{tabular}


Table 8: VAS Score

\begin{tabular}{|c|c|c|c|c|}
\hline Variables & Mean & Standard Deviation & $P$ value & Significant \\
\hline At the time of Injection & 8.804 & 1.288 & \multirow{2}{*}{$<0.0001 * * *$} & \multirow{2}{*}{ HS } \\
\hline $1^{\text {st }}$ Month & 6.980 & 1.592 & & \\
\hline $1^{\text {st }}$ Month & 6.980 & 1.592 & \multirow{2}{*}{$<0.0001 * * *$} & \multirow{2}{*}{ HS } \\
\hline $2^{\text {nd }}$ Month & 5.088 & 1.623 & & \\
\hline $2^{\text {nd }}$ Month & 5.088 & 1.623 & \multirow{2}{*}{$<0.0001 * * *$} & \multirow{2}{*}{ HS } \\
\hline $4^{\text {th }}$ Month & 2.990 & 1.686 & & \\
\hline $4^{\text {th }}$ Month & 2.990 & 1.686 & \multirow{2}{*}{$<0.0001 * * *$} & \multirow{2}{*}{ HS } \\
\hline $6^{\text {th }}$ Month & 1.186 & 1.892 & & \\
\hline $2^{\text {nd }}$ Month & 5.088 & 1.623 & \multirow{2}{*}{$<0.0001 * * *$} & \multirow{2}{*}{ HS } \\
\hline $6^{\text {th }}$ Month & 1.186 & 1.892 & & \\
\hline At the time of Injection & 8.804 & 1.288 & \multirow{2}{*}{$<0.0001 * * *$} & \multirow{2}{*}{ HS } \\
\hline $6^{\text {th }}$ Month & 1.186 & 1.892 & & \\
\hline
\end{tabular}

$\mathrm{P} \leq 0.05$ is significant, NS- Not significant, HS- Highly significant

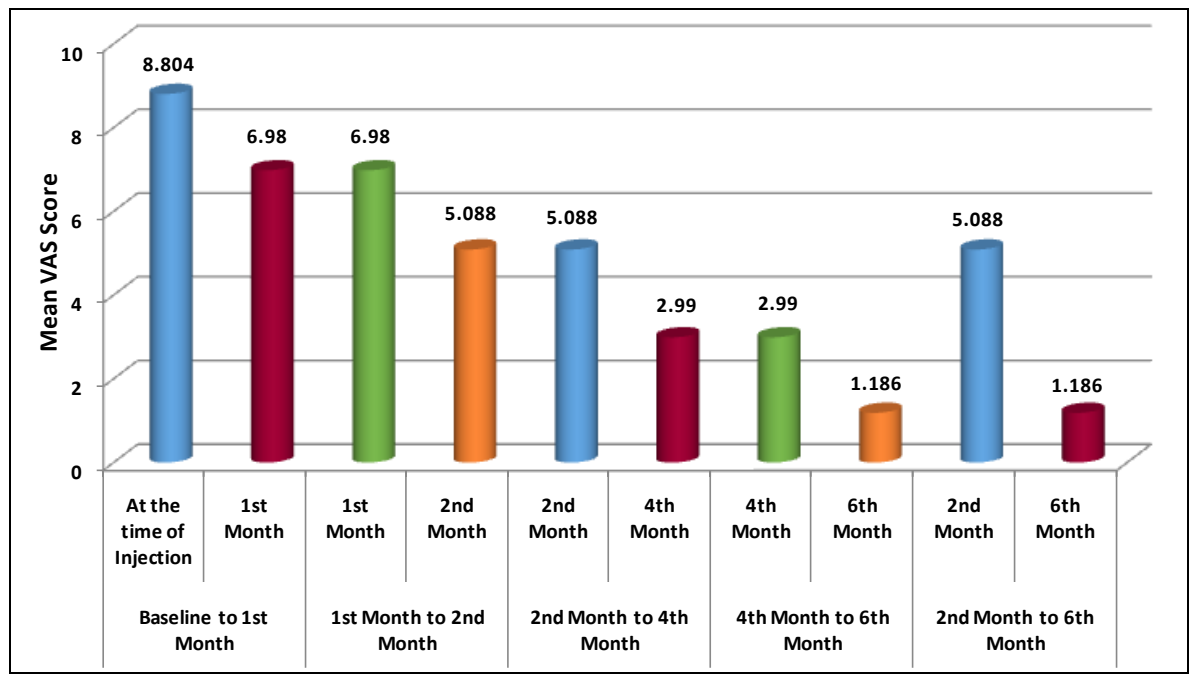

Table 9: Ankle Hind Foot Scale

\begin{tabular}{|c|c|c|c|c|}
\hline Variables & Minimum & Maximum & Mean & Standard Deviation \\
\hline Pre- Injection Score & 44.00 & 73.00 & 54.09 & 6.835 \\
\hline $1^{\text {st }}$ Month & 41.00 & 88.00 & 68.60 & 11.3 \\
\hline $2^{\text {nd }}$ Month & 58.00 & 100.0 & 79.94 & 6.575 \\
\hline $4^{\text {th }}$ Month & 58.00 & 100.0 & 87.63 & 6.766 \\
\hline $6^{\text {th }}$ Month & 58.00 & 100.0 & 94.58 & 8.814 \\
\hline
\end{tabular}

Table 10: Ankle Hind Foot Scale

\begin{tabular}{|c|c|c|c|c|}
\hline Variables & Mean & Standard Deviation & P value & Significant \\
\hline Pre- Injection Score & 54.09 & 6.835 & \multirow{2}{*}{$<0.0001 * * *$} & \multirow{2}{*}{$\mathrm{HS}$} \\
\hline $1^{\text {st }}$ Month & 68.60 & 11.3 & & \\
\hline $1^{\text {st }}$ Month & 68.60 & 11.3 & \multirow{2}{*}{$<0.0001 * * *$} & \multirow{2}{*}{ HS } \\
\hline $2^{\text {nd }}$ Month & 79.94 & 6.575 & & \\
\hline $2^{\text {nd }}$ Month & 79.94 & 6.575 & \multirow{2}{*}{$<0.0001 * * *$} & \multirow{2}{*}{ HS } \\
\hline $4^{\text {th }}$ Month & 87.63 & 6.766 & & \\
\hline $4^{\text {th }}$ Month & 87.63 & 6.766 & \multirow{2}{*}{$<0.0001 * * *$} & \multirow{2}{*}{ HS } \\
\hline $6^{\text {th }}$ Month & 94.58 & 8.814 & & \\
\hline $2^{\text {nd }}$ Month & 79.94 & 6.575 & \multirow{2}{*}{$<0.0001 * * *$} & \multirow{2}{*}{$\mathrm{HS}$} \\
\hline $6^{\text {th }}$ Month & 94.58 & 8.814 & & \\
\hline Pre- Injection Score & 54.09 & 6.835 & \multirow{2}{*}{$<0.0001 * * *$} & \multirow{2}{*}{$\mathrm{HS}$} \\
\hline $6^{\text {th }}$ Month & 94.58 & 8.814 & & \\
\hline
\end{tabular}

$\mathrm{P} \leq 0.05$ is significant, NS- Not significant, HS- Highly significant 


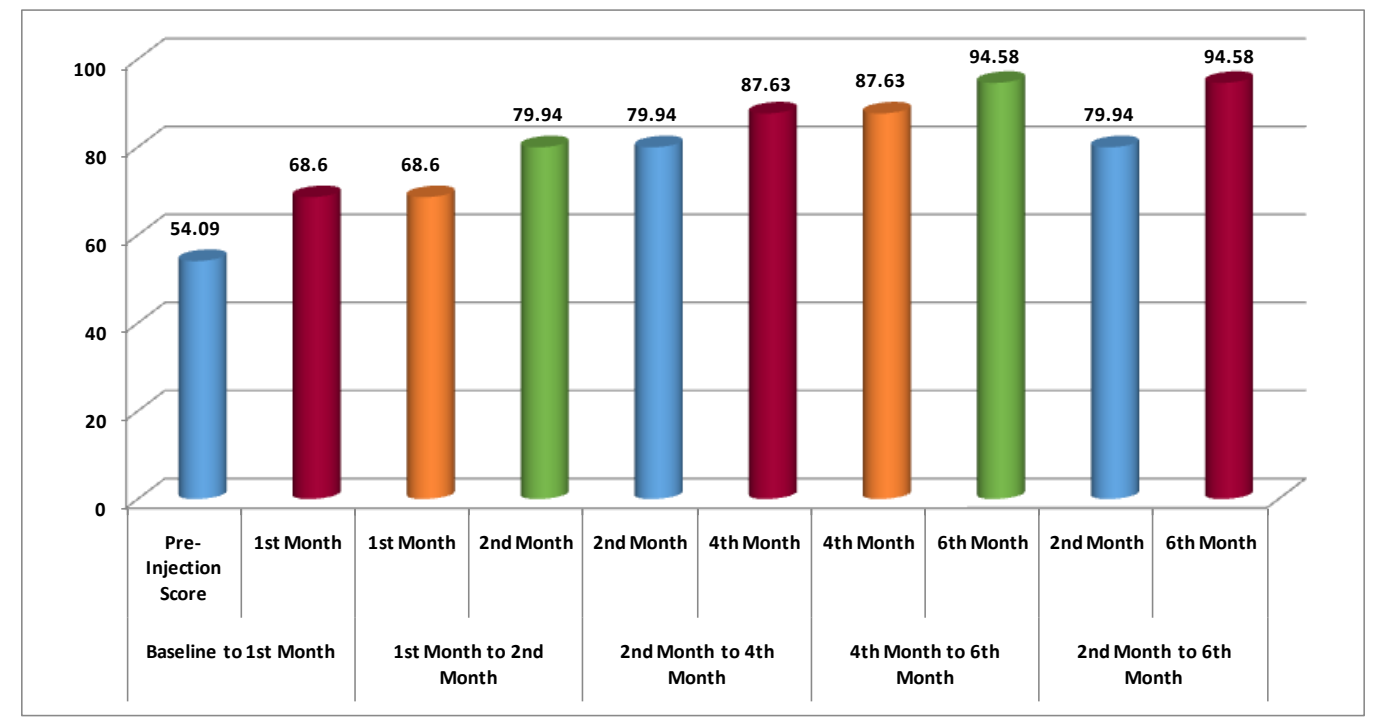

When comparing the significance of pain reduction it was found that there was highly significant pain reduction present all the months.

\section{Platelet-rich plasma is injected into each of the marked spots with the dry needling technique (PEPPERING)}

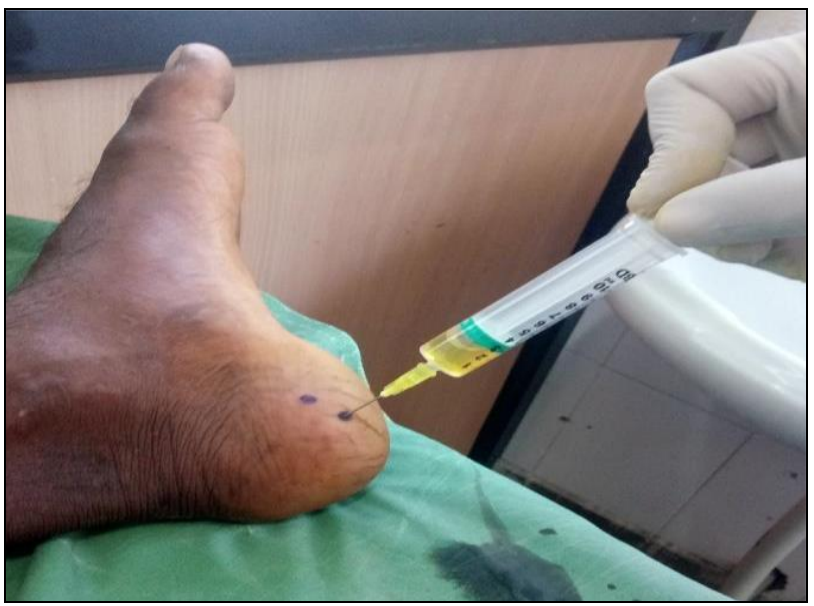

\section{Conclusion}

\section{We Conclude}

Autologous PRP injection is a safe and useful modality for treatment of chronic plantar fasciitis. The response of patients with plantar fasciitis was significantly increased. PRP therapy shows healing of the damaged and inflamed plantar fascia. PRP injection has safety and efficiency in treatment of plantar fasciitis with no side effects and complications.

\section{Acknowledgements}

We thank our colleagues from Sri Siddhartha Academy of Higher Education who provided insight and expertise that greatly assisted the research.

We thank faculty of Department of orthopaedics, Sri siidhartha medical college, affiliated to Sri Siddhartha Academy of Higher Education for assistance and for comments that greatly improved the manuscript.

\section{Declarations}

Funding: none

Conflict of interest: none

Ethical approval: Approved by ethical committee

\section{References}

1. Cornwall MW, McPoil TG. Plantar fasciitis: Etiology and treatment. J Ortho Sports Phys Ther. 1999; 9:756-756.

2. Young CC, Rutherford DS, Niedfelt MW. Treatment of plantar fasciitis. Am Fam Physician. 2001; 63:467-74, 477-478.

3. Lapidus PW, Guidotti FP. Painful heel: report of 323 patients with 364 painful heels. Clinical Orthopaedics \& Related Research, 1965; 39:178-86.

4. Davies MS, Weiss GA, Saxby TS. Plantar fasciitis: how successful is surgical intervention?. Foot \& Ankle International, 1999; 20:803-7.

5. Cullen NP, Singh D. Plantar fasciitis: a review. Br J Hosp Med (Lond). 2006; 67:72-76.

6. Lynch DM, Goforth WP, Martin JE, Odom RD, preece CK, Kotter MW. Conservation treatment of plantar of plantar fasciitis. A prospective study. J Am Podiatr Med Assoc. 1998; 88:375-380.

7. Pankaj Mahidar, chronic plantar fasciitis: effects of PRP, corticosteroid, placebo. Received: March 27, 2014; Accepted: June 24, 2014. doi: 10.3928/0147744720160222-01, orthopaedic e journal.

8. Ferhat say, compare the effects of platelet-rich plasma (PRP) and steroid injections in patients diagnosed with plantar fasciitis. ActaOrthopTraumatolTurc 2014; 48(6):667- 672 doi: 10.3944/AOTT.2014.13.0142

9. Ragab EM, Othman AM. Platelet rich plasma for treatment of chronic plantar fasciitis. Arch Orthop Trauma Surg. 2012; 132:1065-70.

10. MukeshTiwari, platelet rich plasma therapy, a comparative effective therapy with promising result in plantar fasciitis. Journal of clinical orthopaedic and trauma, 2013; 4:31-35.

11. Akfirat M, Sen C, Gunes T. Ultrasonographic appearance of the plantar fasciitis clin inaging. 2003; 27:353-357.

12. Rahim A, Tiwari M. Plantar fasciitis: outcome evaluation of plantar fasciitis treated with PRP against steroid injection. IAIM, 2015; 2(2):46-51. 